\title{
Princípios de Sustentabilidade para Reabilitação de Assentamentos Urbanos: o caso da ARIS Pôr do Sol - Ceilândia/DF1
}

\section{Principles of Sustainability for Rehabilitation of Urban Settlements: the case of ARIS Pôr do Sol - Ceilândia / DF}

\author{
Cordeiro, Márcia'; Andrade, Liza² \\ 1 Universidade de Brasília, SQN 112 Bloco E AP-504, Brasil, \\ arq.marcia.cordeiro@gmail.com \\ 2 Universidade de Brasília, lizamsa@gmail.com
}

\begin{abstract}
RESUMO
Esta pesquisa trata da temática da reabilitação urbana e dos padrões de desenho urbano adequados para transformar o espaço degradado na Área de Regularização de Interesse Social do Pôr do Sol (ARIS Pôr do Sol) nas Bordas da Ceilândia - Distrito Federal. Escolhida por ter elevada importância regional em termos de recursos hídricos e fatores bióticos, com papel fundamental no abastecimento de água de todo o DF. Além disso, a ARIS Pôr do Sol está em fase de regularização fundiária, e as propostas aqui defendidas enfatizam os aspectos de infraestrutura em função da ausência de salubridade urbana, o que a afasta de seu potencial de sustentabilidade e economia baseada na agricultura urbana e gestão dos resíduos sólidos. Assim, esta pesquisa pretende analisar as características ambientais, urbanas e sociais dessa área a fim de contribuir com ações capazes de guiar os atores envolvidos nos programas e projetos responsáveis pelo seu crescimento urbano sustentável. Por isso, os resultados demonstram a vocação ambiental da área, localizada nos limites territoriais de controle ambiental, constituída de solo altamente poroso, o que facilita a recarga aquífera da unidade hidrológica do rio Melchior, na qual está inserida a área de estudo.
\end{abstract}

Palavras-chave: desenho urbano, reabilitação, sustentabilidade.

\begin{abstract}
This research discusses the urban rehabilitation and the suitable urban design patterns to transform the degraded space of the Social Interest Regularization Area (ARIS) in the borders of Ceilândia - Federal District (DF) named Pôr do Sol. This area was chosen for its high regional importance in terms of water resources and biotic factors, developing a fundamental role for water supplies throughout the DF. In addition, ARIS Pôr do Sol is in a land regularization process, and for that, this work emphasizes in proposals of infrastructure aspects due to the absence of urban sanitation. These aspects distance it from its potential for sustainability and economy based on urban agriculture and management of solid residues. Thus, this research intends to analyze the environmental, urban and social characteristics of this area in order to contribute or to guide the actions of the agents involved in the programs and projects responsible for their
\end{abstract}

${ }^{1}$ CORDEIRO, W.; ANDRADE, L. Princípios de Sustentabilidade para Reabilitação de Assentamentos Urbanos: o caso da ARIS Pôr do Sol - Ceilândia/DF. In: II SIMPÓSIO NACIONAL DE GESTÃO E ENGENHARIA URBANA: SINGEURB, 2019, São Paulo. Anais... Porto Alegre: ANTAC, 2019. 
sustainable urban growth. Therefore, the results demonstrated the environmental vocation of the area, in an environmental control territory, consisting of highly porous soils, which eases up the hydrological recharge unit of the Melchior river, where the study area is placed.

Key words: urban design, rehabilitation, sustainability

\section{INTRODUÇÃO}

A resiliência urbana tem alta capacidade de superar adversidades e se renovar, respondendo à escassez de recursos naturais, às mudanças climáticas e aos problemas sociais de forma mais eficaz. Nesse sentido, a configuração dos elementos estruturadores da cidade, os padrões espaciais e a participação da comunidade tornam-se elementos-chave para alcançá-la (ANDRADE, 2014).

Embora a urbanização mais utilizada nas cidades seja a infraestrutura cinza - focada no automóvel, para Herzog (2009) a cidade resiliente se contrapõe a esse modelo por ter estreita ligação com o urbanismo ecológico. Consegue assim, tratar disciplinas semelhantes, as quais levam em consideração soluções baseadas na infraestrutura verde, aspecto essencial considerado neste estudo.

Este estudo propõe-se analisar a sistemática das cidades resilientes e adaptá-la ao espaço construído da Área de Regularização de Interesse Social do Pôr do Sol (ARIS Pôr do Sol Ceilândia/DF). Com isso, procura obter melhores condições de vida para a população residente e proteção das áreas de preservação circundantes a esse sítio urbano, orientandose pelas soluções baseadas na natureza.

Figura 1 - Localização da ARIS Pôr do Sol no território Nacional e Distrital

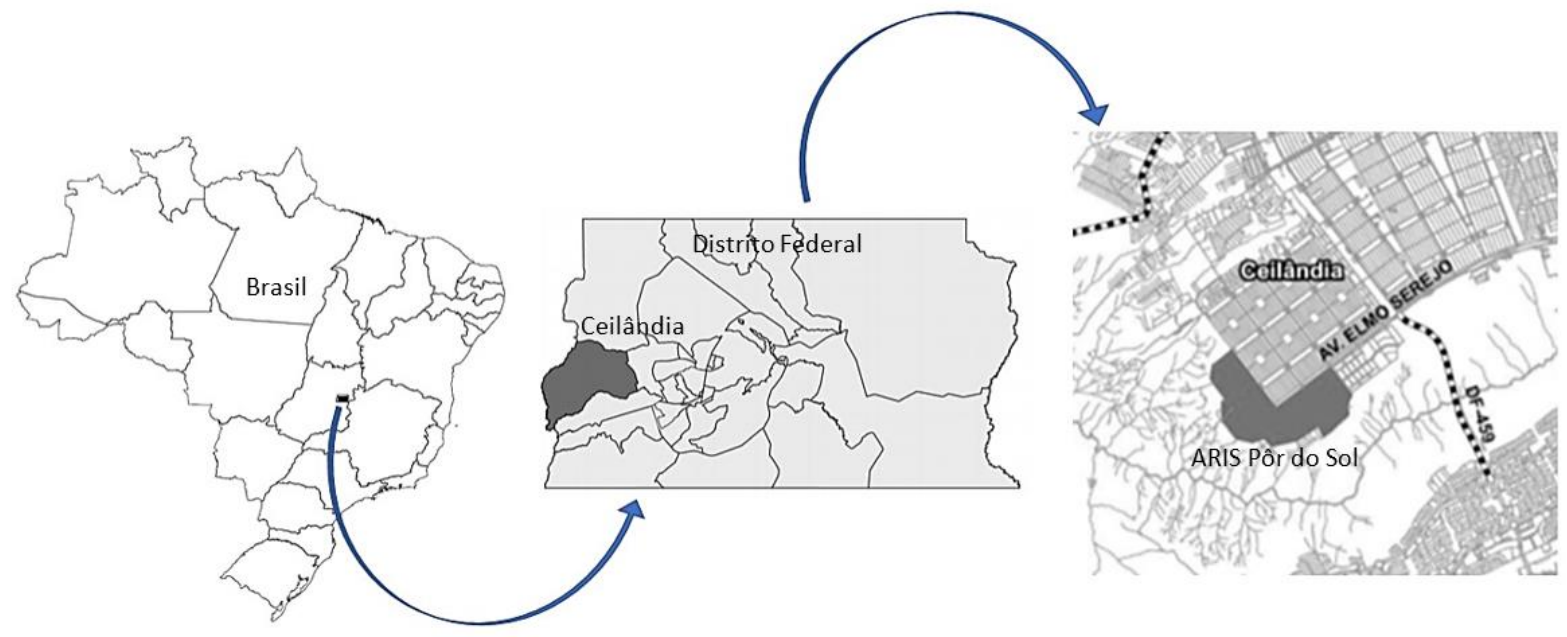

Fonte: Montagem de imagens retiradas do Google, 2019

É imprescindível destacar que o desenvolvimento da morfologia das cidades sofre influência de duas características significativas para o meio ambiente. Uma delas refere-se ao modelo com alta densidade, onde o uso do solo é compacto para melhor aproveitar a infraestrutura urbana existente, reduzir custos de instalação de serviços e consumo de materiais (RUEDA, 2000).

A outra vertente concentra-se no conceito do desenho voltado para a paisagem, com espaço construído disperso e baixa densidade populacional, na qual são essenciais as tecnologias de infraestrutura baseadas na natureza (ANDRADE, 2014).

Ao aplicar essa dualidade urbana ao contexto da ARIS Pôr do Sol, podemos verificar que a área se aproxima da vertente de cidade compacta. Pois, sua estrutura espacial é massificada 
e não observa os limites ambientais quase em sua totalidade, particularidade de aglomerações urbanas iniciadas irregularmente.

A ARIS Pôr do Sol situa-se, em grande parte, dentro da região das Bordas da Ceilândia, compreendida entre os limites territoriais da Ceilândia e da área rural de Samambaia.

Para compor essa análise, foram utilizados princípios do urbanismo ecológico e de sustentabilidade aplicados ao desenho urbano por se tratar de uma região de extrema relevância em termos de recursos hídricos, envolvida pela Área de Relevante Interesse Ecológico do Parque Juscelino Kubistchek - ARIE Parque JK.

Figura 2 - Limites da ARIE Parque JK (cor verde)

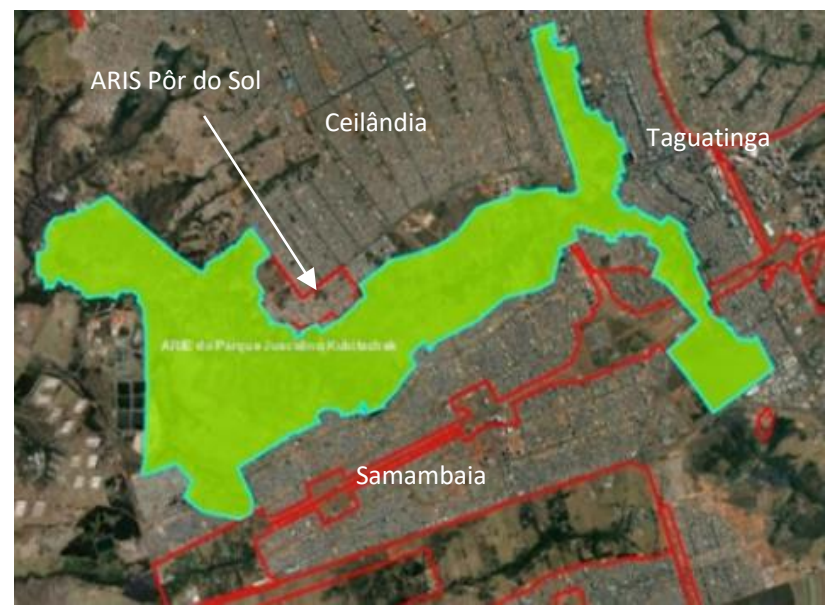

Fonte: Imagem retirada do site Geoportal/DF, 2019

Espera-se que os instrumentos de sustentabilidade descritos nesta pesquisa sirvam de referência para outros parcelamentos com equivalências estruturais urbanas às da ARIS Pôr do Sol para que viabilizem um roteiro apropriado de ações e implementem estratégias de investimentos financeiros dos órgãos de gestão pública envolvidos na resolução das demandas urbanas.

\section{METODOLOGIA DOS PRINCÍPIOS DE SUSTENTABILIDADE APLICADOS A ARIS PÔR DO SOL}

A análise que segue foi realizada com base nos estudos de Andrade (2014), que tratam do conceito de resiliência e dos princípios de sustentabilidade aplicados ao desenho urbano como ferramenta de adaptação para tornar as cidades resilientes.

A pesquisa foi constituída do diagnóstico ambiental com base no Estudo de Impacto Ambiental e Relatório de Impacto Ambiental da ARIS Pôr do Sol (PROGEA, 2009). Para tanto utilizou o levantamento e a qualificação dos dados coletados, em busca dos principais aspectos de caracterização da área, uso e ocupação do solo, bem como os impactos e medidas mitigadoras.

Concomitante a essa análise, definiu indicadores de princípios ecológicos que promovam o desenvolvimento sustentável da região amparados nas Diretrizes Urbanísticas Específicas para as Bordas da Ceilândia - Pôr do Sol (DIUR, 2016).

A aplicação desse estudo tem a finalidade de induzir os processos de instalação dos dispositivos de infraestrutura verde em área/lote já consolidados na ARIS Pôr do Sol, onde houver viabilidade estrutural. 
Assim, esta pesquisa acredita que uma vez dirimidas essas questões de infraestrutura, as demais estruturas terão maiores chances de serem executadas de maneira sustentável, barrando a degradação ambiental e proporcionando qualidade de vida a população local.

\section{RESULTADOS DA APLICAÇÃO DOS PRINCÍPIOS DE SUSTENTABILIDADE EMPREGADOS NA ARIS PÔR DO SOL}

Segundo o Relatório de Impacto Ambiental, na região predominam os aspectos negativos de um imenso passivo ambiental representado pelos assentamentos, configurados de forma desconexa, carentes de infraestrutura e de serviços públicos urbanos.

Toda essa dinâmica gera insalubridade para a população local e baixa qualidade de vida promovendo a exclusão social. Esses fatores limitam o desenvolvimento sustentável, em especial da ARIS Pôr do Sol, por se tratar de enclave territorial em zona de amortecimento ambiental (PROGEA, 2009).

Conforme o Zoneamento Ecológico-Econômico do Distrito Federal - ZEE-DF (Lei n. ${ }^{\circ}$ 6.269/2019) há na ARIS do Pôr do Sol um risco ecológico de perda de solo por erosão qualificado como muito alto, causado pela ausência de estrutura de drenagem apropriada ao lugar.

A utilização de infraestrutura cinza agrava o processo de deterioração do ecossistema local porque vem sendo implantada sem observar parâmetros mínimos de mitigação dos impactos que essa escolha estrutural provoca.

Além dos efeitos nocivos advindos do desrespeito ao que propõe o Zoneamento da Área de Proteção Ambiental do Planalto Central, Figura 3 a seguir:

Figura 3 - Poligonal ARIS Pôr do Sol - Zoneamento da APA do Planalto Central

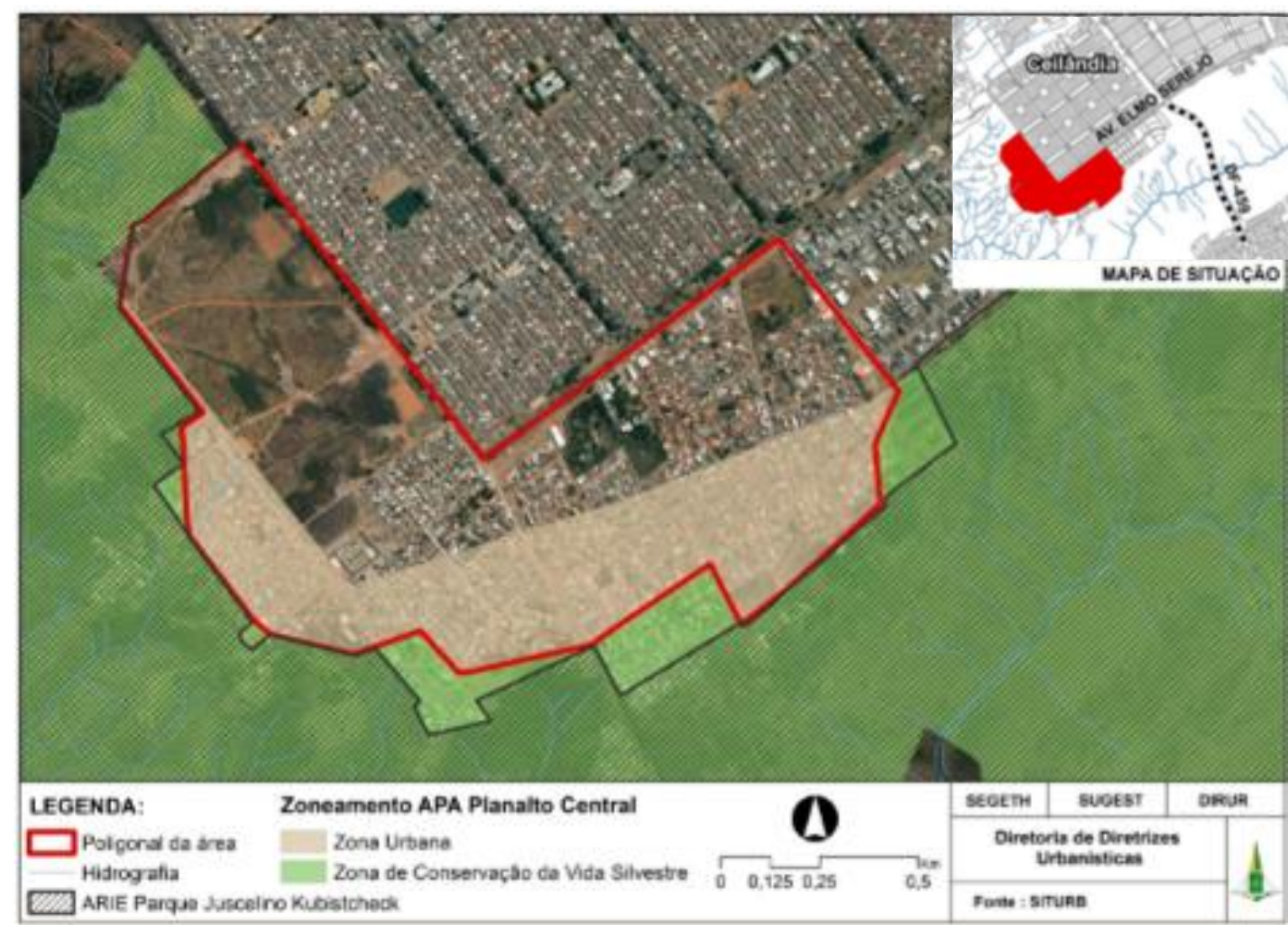

Fonte: DIUR - 09/2016 - Governo do Distrito Federal 


\subsection{Princípios de Sustentabilidade aplicados a ARIS Pôr do Sol}

Com base na verificação do Estudo de Impacto Ambiental ${ }^{2}$ existente e nas diretrizes propostas pela SEDUH/DF3, os resultados obtidos através da aplicação dos princípios de sustentabilidade embasados no modelo de Andrade (2014) mostraram que para cada nicho estrutural urbano estudado pôde-se aplicar ao menos uma técnica urbana sustentável.

A comparação evidenciou algumas medidas de aplicabilidade mais urgentes na elaboração de um plano de drenagem urbana natural capaz de desacelerar os efeitos nocivos da expansão urbana ocorrida naquela região, como mostra o Quadro 1:

Quadro 1 - Princípios de sustentabilidade aplicados a ARIS Pôr do Sol baseados em Andrade (2014)

\begin{tabular}{|c|c|c|}
\hline PRINCÍPIOS & ESTRATÉGIAS DE PLANEJAMENTO & $\begin{array}{l}\text { TÉCNICAS URBANAS } \\
\text { (Recomendações específicas) }\end{array}$ \\
\hline Adensamento Urbano & $\begin{array}{l}\text { Este estudo propõe que as áreas de } \\
\text { maior densidade sejam ao longo da } \\
\text { Avenida Elmo Serejo, onde já existe uma } \\
\text { tendência de uso comercial/residencial. }\end{array}$ & $\begin{array}{l}\text { Usos diversificados e proibição } \\
\text { do uso residencial exclusivo ao } \\
\text { longo da Avenida Elmo Serejo. } \\
\text { Altura máxima das edificações } \\
\text { até } 30 \mathrm{~m} \text { a taxa de } \\
\text { permeabilidade de } 10 \% \text { no } \\
\text { mínimo. } \\
\text { Edificações agrupadas para } \\
\text { reduzir as redes de } \\
\text { infraestrutura e impulsionar a } \\
\text { mobilidade sustentável. }\end{array}$ \\
\hline Drenagem Natural & $\begin{array}{l}\text { Regenerar o ciclo hidrológico para a } \\
\text { região do ribeirão Taguatinga e rio } \\
\text { Melchior. } \\
\text { Readequar as redes de águas pluviais } \\
\text { provenientes do P Sul/Ceilândia e } \\
\text { implementar o aproveitamento de águas } \\
\text { residuais. }\end{array}$ & $\begin{array}{l}\text { Revitalização dos vazios } \\
\text { urbanos, utilizando drenagem } \\
\text { natural e desenho da } \\
\text { paisagem. } \\
\text { Evitar que córregos não sejam } \\
\text { enterrados nem canalizados. } \\
\text { Aproveitamento de águas } \\
\text { pluviais e pavimentos } \\
\text { permeáveis. } \\
\text { Criação de bacias de } \\
\text { contenção para diminuir a } \\
\text { erosão. }\end{array}$ \\
\hline $\begin{array}{l}\text { Economia Local / } \\
\text { Centros de Bairros }\end{array}$ & $\begin{array}{l}\text { Promover a autonomia econômica da } \\
\text { ARIS Pôr do Sol através das áreas } \\
\text { comerciais, próximas ao P Sul e a ADE } \\
\text { Centro Norte. }\end{array}$ & $\begin{array}{l}\text { Estimular a vocação comercial } \\
\text { da área com permissão legal } \\
\text { para uso misto e lotes maiores } \\
\text { intercalados com os lotes } \\
\text { residenciais. }\end{array}$ \\
\hline $\begin{array}{l}\text { Gestão integrada da } \\
\text { água }\end{array}$ & $\begin{array}{l}\text { Há a necessidade de aproveitamento de } \\
\text { água pluviais e o tratamento de águas } \\
\text { residuais para reduzir o uso de água do } \\
\text { sistema da concessionária e incentivar a } \\
\text { regeneração do ciclo hidrológico. }\end{array}$ & $\begin{array}{l}\text { Reaproveitamento das águas } \\
\text { servidas nos projetos de } \\
\text { arquitetura. } \\
\text { Calhas para captar água e } \\
\text { reservatórios, onde a água } \\
\text { coletada pode ter diversos fins. }\end{array}$ \\
\hline
\end{tabular}

\footnotetext{
2 Estudo de Impacto Ambiental / PROGEA, 2009.

${ }^{3}$ Diretrizes Urbanísticas - DIUR 09-2016/Secretaria de Desenvolvimento e Habitação - SEDUH/DF
} 


\begin{tabular}{|c|c|c|}
\hline Mobilidade sustentável & $\begin{array}{l}\text { Aproveitar os vazios urbanos de algumas } \\
\text { ruas para as atividades urbanas, a fim de } \\
\text { incentivar a população a fazer os } \\
\text { percursos a pé ou de bicicleta. } \\
\text { Priorizar a Avenida Elmo Serejo como } \\
\text { "centro de bairro" por meio de } \\
\text { integração de usos. }\end{array}$ & $\begin{array}{l}\text { Revitalização do sistema viário } \\
\text { com instalação de ciclovias e } \\
\text { passeios arborizados, acessíveis } \\
\text { e iluminados. } \\
\text { Sinalização viária com } \\
\text { redutores de velocidade e } \\
\text { faixas de pedestres. } \\
\text { Ruas compartilhadas nas vias } \\
\text { locais e nas ruas sem saída. } \\
\text { Integrar o sistema de transporte } \\
\text { público com o modal não } \\
\text { motorizado. }\end{array}$ \\
\hline Política dos 3R's & $\begin{array}{l}\text { Promover a redução do consumo de } \\
\text { água da rede de distribuição geral. } \\
\text { Incentivar a coleta seletiva, instalar } \\
\text { postos de coleta de entulho e } \\
\text { reciclagem do lixo orgânico. }\end{array}$ & $\begin{array}{l}\text { Realocar as ocupações da } \\
\text { área do antigo aterro. } \\
\text { Educar a população sobre a } \\
\text { prática nociva de jogar lixo nas } \\
\text { vias públicas. } \\
\text { Constituição de associação } \\
\text { para os catadores de material } \\
\text { reciclável. } \\
\text { Criação de hortas comunitárias } \\
\text { e individuais. }\end{array}$ \\
\hline Proteção ecológica & $\begin{array}{l}\text { Implantar medidas de proteção } \\
\text { ambiental para ARIE Parque JK, evitando } \\
\text { a expansão urbana sobre essa área de } \\
\text { proteção permanente. } \\
\text { Ocupar os vazios urbanos com áreas } \\
\text { verdes e paisagismo produtivo. }\end{array}$ & $\begin{array}{l}\text { Recuperação de nascentes e } \\
\text { corredores ecológicos. } \\
\text { Promover a agricultura urbana } \\
\text { e paisagismo produtivo. }\end{array}$ \\
\hline $\begin{array}{l}\text { Revitalização urbana e } \\
\text { sentido de vizinhança }\end{array}$ & $\begin{array}{l}\text { Instalação de equipamentos públicos de } \\
\text { lazer e esporte. } \\
\text { Criar oportunidades de realizar as } \\
\text { atividades diárias dentro da própria } \\
\text { vizinhança. } \\
\text { Adotar práticas locais de serviços e } \\
\text { integração dos moradores da região e } \\
\text { do entorno. }\end{array}$ & $\begin{array}{l}\text { Projetar espaços públicos que } \\
\text { propiciem encontros e } \\
\text { trabalhos conjuntos. } \\
\text { Desenvolver um sentido de } \\
\text { lugar com respeito a } \\
\text { preservação da ARIE Parque } \\
\text { JK. } \\
\text { Criar um centro de atividades } \\
\text { para as dinâmicas sociais } \\
\text { comunitárias. } \\
\text { Criação de pequenos largos, } \\
\text { passagem para pedestres e } \\
\text { ciclovias. }\end{array}$ \\
\hline
\end{tabular}

Fonte: Conexões dos Padrões Espaciais dos Ecossistemas Urbanos (Andrade, 2014)

\section{CONCLUSÕES}

Em conformidade com a análise de impactos ambientais e as estratégias ecológicas orientadoras do planejamento urbano, este estudo verificou que na ARIS Pôr do Sol há uma predominância de lotes residenciais, comércio local fragmentado, ausência de áreas verdes e pontos de encontro comunitário. 
A configuração urbana presente a qualifica como um assentamento compactado, formado pelo contexto de cidade-dormitório e acentuada dependência de serviços de toda esfera das cidades mais próximas: Ceilândia, Taguatinga e Samambaia.

Conforme o Relatório de Impacto Ambiental, o sistema viário não possui infraestrutura de drenagem e a maioria das ruas tem revestimento precário, com deposição de entulho e lixo em grande parte de suas extensões, o que compromete a mobilidade sustentável.

Apesar do desenho urbano das vias ser constituído por malha ortogonal, desconsiderou os aspectos de declividade natural do terreno, tubulação existente, hierarquização viária, passeio e arborização.

Portanto, uma vez dirimidas as questões de infraestrutura baseadas na gestão integrada da água e no manejo natural da drenagem pluvial, as demais estruturas da ARIS Pôr do Sol terão maiores chances de serem executadas de maneira sustentável, barrando a degradação ambiental que avança sobre a ARIE Parque JK e melhorando a qualidade de vida da população local.

\section{REFERÊNCIAS BIBLIOGRÁFICAS}

ANDRADE, Liza Maria Souza. Conexão dos Padrões Espaciais dos Ecossistemas Urbanos. Brasília, junho de 2014.

GOVERNO DO DISTRITO FEDERAL/Secretaria de Estado de Gestão do Território e Habitação SEGETH/DF. Diretrizes Urbanísticas Específicas (DIUR - 09/2016): Região ARIS Pôr do Sol, Ceilândia/DF. Brasília, 2016.

GOVERNO DO DISTRITO FEDERAL - GDF. Lei Complementar n. ${ }^{\circ} 6.269$, de 29 de janeiro de 2019.

HERZOG, Cecília Polacow. Cidades Para Todos - (re)aprendendo a Conviver Com a Natureza. Rio de Janeiro: Editora MAUAD, 2013

PROGEA - Engenharia e Estudos Ambientais. Relatório de Impacto Ambiental - RIMA, Avaliação das Ocupações Irregulares nas Bordas da Ceilândia. Brasília, 2009.

PROGEA - Engenharia e Estudos Ambientais. Estudo de Impacto Ambiental - EIA, Avaliação das Ocupações Irregulares nas Bordas da Ceilândia. Brasília, 2009. 